\title{
The Lepra Evaluation Project (LEP), an epidemiological study of leprosy in northern Malawii. II: Prevalence rates
}

\author{
J M PONNIGHAUS, $*$ P E M FINE, $\dagger \ddagger \mathrm{N}$ MAINE, $\dagger$ \\ L BLISS, $\dagger \mathrm{M}$ KALAMBO, ${ }^{*} \&$ ITA PONNIGHAUS* \\ *Lepra Evaluation Project, PO Box 46, Chilumba, Karonga \\ District, Malawi i; †Department of Tropical Hygiene, London \\ School of Hygiene and Tropical Medicine, Keppel Street, London \\ WC1E 7 HT
}

\section{Accepted for publication 4 December 1987}

Summary Prevalence data obtained during a population survey carried out by the Lepra Evaluation Project (LEP) in Karonga District in Northern Malawi (Central Africa) are presented and analysed. Three different prevalence measures are presented: of individuals with current clinical leprosy who are likely to benefit from (further) antileprosy treatment (the 'clinical' prevalence rate), of individuals with either current clinical leprosy or residual signs only (the 'visible' prevalence rate), and of individuals with any physical or historical evidence of present or past leprosy (the 'cumulative' prevalence rate). Effects of past treatment and leprosy control efforts come to light in the difference between the 'visible' rate and the 'cumulative' rate and indicate that about $61 \%$ of the leprosy patients in this area who have received antileprosy treatment in the past, from the Lepra Control Project, are now without remaining signs of clinical leprosy. Past BCG vaccination campaigns and active case finding through school surveys appear to have affected the current age and sex patterns of the disease. Prevalence rates are higher among females than males in the older age groups. The paper demonstrates how the observed pattern and extent of leprosy are a function of the prevalence measure used.

\section{Introduction}

Estimation of the number and proportion of individuals with leprosy in a population is important but difficult. Most of the prevalence information available to health ministries and recorded in the literature is drawn from control programmes. Such statistics are heavily influenced by methods and policy changes in case detection, diagnosis, registration, duration of treatment and release from control, and may be misleading. ${ }^{1}$

The alternatives to routine control programme data are estimates derived from specially organized surveys. Despite their cost, large scale surveys have been carried out in a number of countries in recent decades, providing descriptions of leprosy prevalence in the Philippines, ${ }^{2}$

$\ddagger$ Reprint requests: Dr P Fine-see above for address. 
Thailand, ${ }^{3}$ Burma, ${ }^{4}$ South India ${ }^{5}$ and West Africa. ${ }^{3}$ In general these surveys have indicated that the prevalence rate of leprosy in endemic areas increases with age up to a plateau at 20-40 years, after which it may fall. Prevalence rates are generally reported to be higher among males than among females, in particular for multibacillary disease. ${ }^{6}$ Beyond these generalities, the published data suggest that the pattern of leprosy varies greatly between different areas of the world in terms of its overall frequency and its distribution by age, sex and clinical classification. The implications of this variation, and to what extent it may reflect biological differences between populations, or methodological differences in case definitions or in the designs of the several studies, are unclear.

A major problem in any epidemiological investigation is that of case definition. What is the 'leprosy' whose prevalence is being measured? In a separate publication we have discussed the problem of defining a case in terms of deciding whether or not an individual has, or has had, disease attributable to Mycobacterium leprae. ${ }^{7}$ But that is not the only definition problem in measuring the

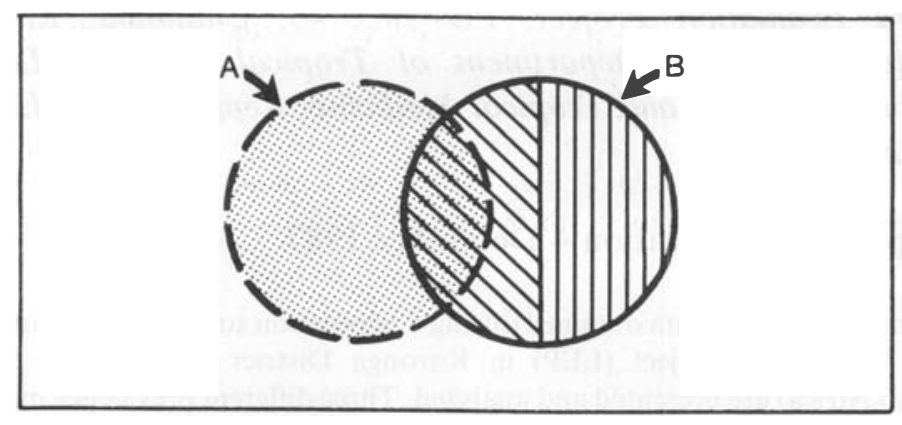

$A=$ Individuals currently infected with $\underline{M}$. leprae
$B=$ Current or past leprosy patients

$\square=$ Individuals never infected with $\underline{M}$. leprae

ह = Individuals currently infected with M. leprae but without clinical signs of lepros $\bar{y}$

= Individuals currently infected with $\underline{M}$. leprae and with current clinical leprosy

NV = Individuals not infected with $\underline{M}$. leprae but with

या = Individuals without remaining signs of, but documented history of clinical leprosy

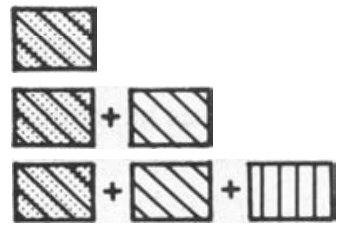

$=$ Individuals included in clinical prevalence rate

= Individuals included in visible prevalence rate

$=$ Individuals included in cumulative prevalence rate

Figure 1. Relationship between different prevalence measures discussed in this paper. The sizes of the circles is not related to actual rates in Karonga District. The possibility of 'persisters' (dormant M. leprae) in individuals with residual signs of leprosy only and in individuals without remaining evidence of past clinical leprosy has been ignored in this schematic presentation. 
prevalence of leprosy. Ideally we would like to distinguish four different prevalence measures: (1) of infection (implying the presence of living $M$. leprae in the body); (2) of current clinical disease (implying that an individual is infected and that the infection has progressed to a stage where it can be detected clinically, and confirmed if necessary histopathologically or bacteriologically); (3) of visable disease (implying the presence of (clinical) signs attributable to current infection or residual signs of past infection with M. leprae); and (4) of cummulative disease (including all individuals who have ever in their lives manifested clinical leprosy).

Figure 1 shows the relationship between these four different prevalence measures. The first is at present unobtainable, in the absence of sensitive and specific methods for detecting $M$. leprae infection. ${ }^{8}$ Investigators are thus forced to concentrate upon the pattern of clinical and/or residual signs of leprosy only. Unfortunately, very few publications are clear even on this distinction, and on whether 'cured' or 'burnt out' individuals are included as prevalent leprosy cases or not. The situation is exacerbated further by the continued confusion over 'indeterminate leprosy' cases, which are of ten included in prevalence measures though the very diagnosis may be in doubt. ${ }^{9}$

The problem of estimating and describing the pattern of leprosy remains important both for operational reasons in guiding leprosy control and for research purposes of understanding its natural history. In this paper we present and discuss the prevalence of leprosy based on data from the Lepra Evaluation Project (LEP) in Malawii. In so doing we explore different definitions of prevalent leprosy, in order to draw attention to their implications for describing the amount and pattern of leprosy in a community.

\section{Methods}

The methods of the LEP are described in detail in a separate publication. ${ }^{10}$ In this context we note that it began as a total population survey and was carried out in Karonga District, Northern Malawi. More than 112,000 people were interviewed between 1979 and 1984, representing virtually the entire population in all but the southernmost tip of the District. ${ }^{10}$ Leprosy patients were identified by paramedical workers (Leprosy Control Assistants, LCAs) who examined more than $97 \%$ of those interviewed for skin lesions, enlarged nerves and disabilities. All untreated leprosy suspects and suspected relapses were also examined by the project Medical Officer (JMP), but patients already on treatment were examined by JMP as a matter of routine only if they were still clinically active. Biopsies were taken from $95 \%$ of all newly found suspects, examined by Dr A C McDougall and reported in standardized format. ${ }^{11}$ In addition to information collected during the LEP survey, we have had access to all records of the LEPRA Control Project (LCP) which was active in Karonga District since $1973 .{ }^{12}$ In order to analyse the prevalence of leprosy in this population we have categorized all past and present cases according to four different sets of criteria: (1) diagnostic certainty; (2) classification; (3) current status; and (4) period of ascertainment. These categories are described below:

\section{Diagnostic certainty}

All individuals with any evidence of leprosy were assigned to one or another of four groups: (i) a 'narrow' (certain leprosy) group in which the overall level of certainty of the diagnosis leprosy and of the classification is extremely high; (ii) a 'middle' (probably leprosy) group, in which we expect that a high proportion of the individuals included are or were indeed cases of clinical leprosy but accept that a small proportion whose clinical signs were not in fact attributable to $M$. leprae infection will also be included; (iii) a 'wide' (possibly leprosy) group containing only a small proportion of individuals with present or past clinical leprosy; and (iv) an 'out' group, in which the leprosy diagnosis is totally discarded. Individuals in this group can thus be considered to have or have had no evidence of clinical leprosy. 
The method for assigning individuals to one or other of these groups is described elsewhere. ${ }^{7}$ Only 'narrow' (N) and 'middle' (M) group cases are included in the present analysis.

\section{Classification}

For the purpose of this analysis, all cases are classified as either paucibacillary or multibacillary on the basis of clinical diagnosis, which in turn included slit-skin smear information whenever available. Given our evidence, ${ }^{12}$ that there has been a tendency in Malawi to classify patients with bilateral deformities too far towards the lepromatous end of the spectrum we have included borderline (Madrid) and BB (Ridley-Jopling) cases in the paucibacillary group in this analysis. ${ }^{13,14}$ Thus our division is similar but not identical to the one recommended by the 1981 WHO Study Group. ${ }^{1}$

\section{Current status}

We have used the following criteria in order to define the different prevalence measures discussed in the introduction (see Figure 1). Clinical prevalence implies one or both of the following: a positive BI in slit-skin smears or biopsy at the time of first examination by the LEP, or 'clinically active' skin lesions. ('Clinically active' implies that signs of inflammation were present.)

The visible prevalence rate includes, in addition to the above, all individuals with residual signs (i.e. clinically inactive skin lesions and/or typical disabilities) attributable to past infection with $M$. leprae.

Finally, the cumulative prevalence rate includes, in addition to the above, all individuals with a credibly documented history of leprosy in the past. The creation of this prevalence rate thus required a critical review of all past records of the LCP in Karonga District.

\section{Ascertainment}

Cases could be separated according to three distinct modes of ascertainment: ${ }^{10,12}$ (i) those who were originally diagnosed as leprosy patients by some institution or service other than Lepra before being registered by the Lepra Control Project (LCP) or being 'rediscovered' by the LEP; (ii) those who first self-reported to or were found during school surveys by the LCP between 1973 and June 1981 and who had not received antileprosy treatment elsewhere before. (After June 1981 the LCP stopped registering patients independent of the LEP); (iii) those who were first found or selfreported to the LEP during the 1979-84 survey and who neither were known to the LCP nor had a history of having received antileprosy treatment elsewhere before. The large majority of these patients were found by active case finding. In addition to clinical examination findings by a Medical Officer, we also have biopsy results for approximately $95 \%$ of the individuals in this group ${ }^{11}$ and can be more confident about both the diagnosis and the classification of leprosy in these individuals than in individuals ascertained previously.

\section{Results}

Frequency distributions of claimed years of onset of disease are shown for each ascertainment group in Figure 2. This shows that most patients first ascertained by an institution other than the LCP or the LEP reported onset of disease in the fifties and sixties, while most who were first registered by the LCP had onset of disease in the seventies. A large proportion $(201 / 622=32.3 \%)$ of patients newly found during the 1979-84 LEP survey did not know the year of onset, but most claimed that onset occured in the late seventies or early eighties.

Table 1 shows the breakdown by sex and clinical classification of cases included in each ascertainment group. The multibacillary proportion was by far highest among patients who first 


\section{DISTRIBUTION OF TIME OF ONSET BY MODE OF ASCERTAINMENT}
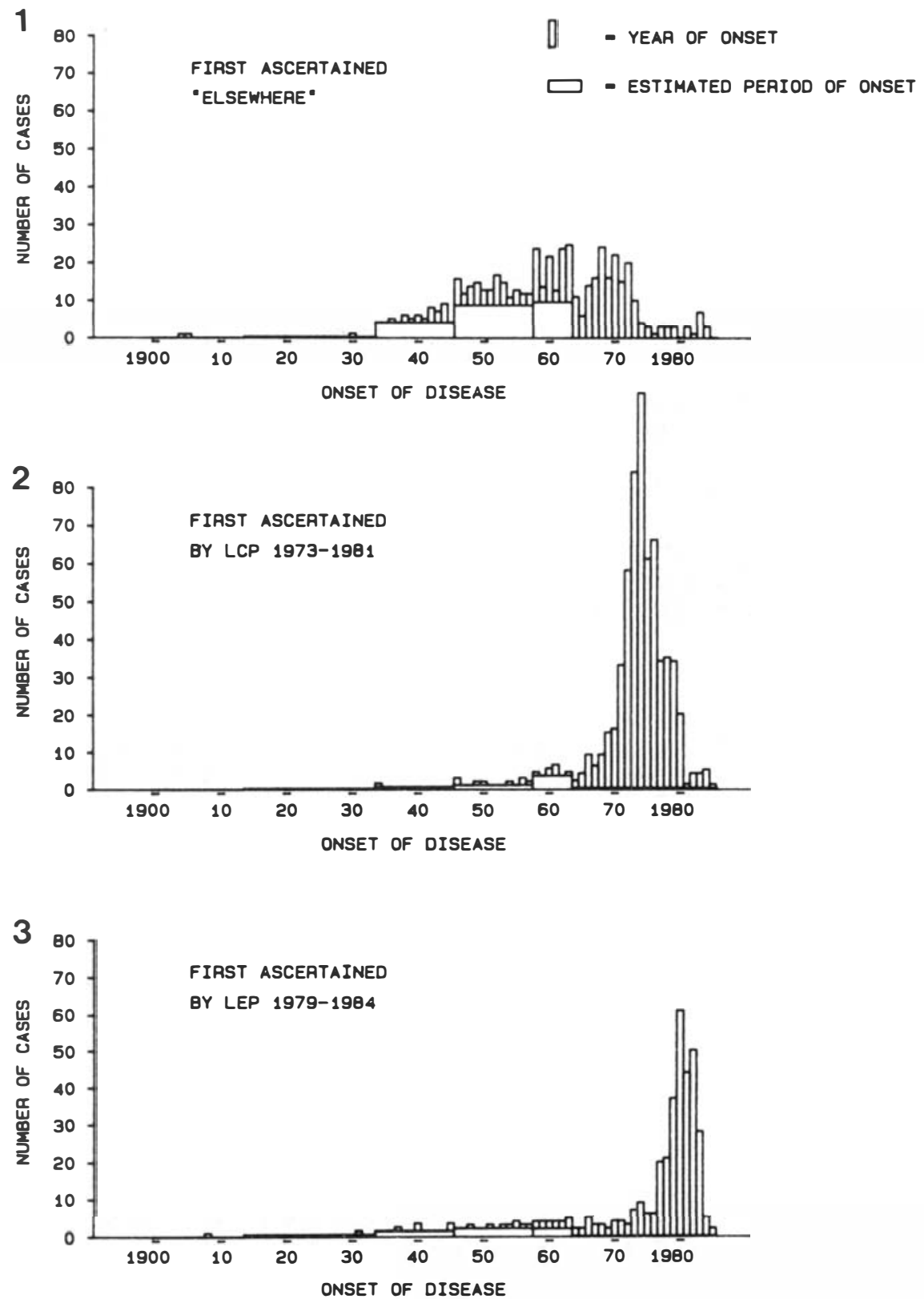

Figure 2. Frequency distributions of years of onset of leprosy (as remembered by the patients) by ascertainment group: (1) patients first ascertained by some organization other than LEPRA; (2) patients first ascertained by the LCP, 1973-81; (3) patients first ascertained by the LEP, 1979-84. 
Table 1. Distribution of leprosy patients by classification, sex and ascertainment group. This table includes all individuals with current or pas clinical signs attributable to infection with $M$. leprae (certainty groups N and M), Karonga District, Malawii, 1979-84

\begin{tabular}{|c|c|c|c|c|c|c|c|}
\hline \multirow[b]{2}{*}{$\begin{array}{l}\text { Ascertainment } \\
\text { group }\end{array}$} & \multicolumn{2}{|c|}{ Males } & \multicolumn{2}{|c|}{ Females } & \multirow[b]{2}{*}{ Total } & \multirow{2}{*}{$\begin{array}{l}\% \text { Females } \\
\text { among all } \\
\text { patients }\end{array}$} & \multirow{2}{*}{$\begin{array}{c}\% \text { Females among } \\
\text { paucibacillary } \\
\text { patients }\end{array}$} \\
\hline & $\begin{array}{c}\text { Paucibacillary } \\
\text { leprosy }\end{array}$ & $\begin{array}{c}\text { Multibacillary } \\
\text { leprosy }\end{array}$ & $\begin{array}{c}\text { Paucibacillary } \\
\text { leprosy }\end{array}$ & $\begin{array}{c}\text { Multibacillary } \\
\text { leprosy }\end{array}$ & & & \\
\hline $\begin{array}{l}\text { Ascertainment } \\
\text { 'elsewhere' }\end{array}$ & $\begin{array}{c}215 \\
(69 \%)\end{array}$ & $\begin{array}{c}96 \\
(31 \%)\end{array}$ & $\begin{array}{c}239 \\
(84 \%)\end{array}$ & $\begin{array}{c}45 \\
(16 \%)\end{array}$ & 595 & 47.7 & $52 \cdot 6$ \\
\hline $\begin{array}{l}\text { Ascertainment } \\
\text { by LCP }\end{array}$ & $\begin{array}{c}355 \\
(93 \%)\end{array}$ & $\begin{array}{c}24 \\
(7 \%)\end{array}$ & $\begin{array}{c}430 \\
(96 \%)\end{array}$ & $\begin{array}{l}16 \\
(4 \%)\end{array}$ & 805 & $55 \cdot 4$ & $56 \cdot 2$ \\
\hline $\begin{array}{l}\text { Ascertainment } \\
\text { by LEP } \\
\text { (excluding } \\
\text { incidence cases) }\end{array}$ & $\begin{array}{c}235 \\
(95 \%)\end{array}$ & $\begin{array}{c}12 \\
(5 \%)\end{array}$ & $\begin{array}{c}373 \\
(99 \%)\end{array}$ & $\begin{array}{c}2 \\
(1 \%)\end{array}$ & 622 & $60 \cdot 3$ & $61 \cdot 3$ \\
\hline Totals & 785 & 132 & 1042 & 63 & 2022 & $54 \cdot 6$ & $57 \cdot 0$ \\
\hline
\end{tabular}


Table 2. Age specific prevalence rates (per 1000 individuals examined) of clinical leprosy among males and females in Karonga District, Malawii, 1979-84

\begin{tabular}{|c|c|c|c|c|c|c|c|c|c|c|c|c|c|c|}
\hline \multirow{3}{*}{$\begin{array}{l}\text { Age at } \\
\text { examination }\end{array}$} & \multicolumn{7}{|c|}{ Males } & \multicolumn{7}{|c|}{ Females } \\
\hline & \multirow{2}{*}{$\begin{array}{c}\text { Total } \\
\text { examined }\end{array}$} & \multicolumn{2}{|c|}{$\begin{array}{c}\text { Paucibacillary } \\
\text { leprosy }\end{array}$} & \multicolumn{2}{|c|}{$\begin{array}{c}\text { Multibacillary } \\
\text { leprosy }\end{array}$} & \multicolumn{2}{|c|}{$\begin{array}{c}\text { All } \\
\text { leprosy }\end{array}$} & \multirow{2}{*}{$\begin{array}{c}\text { Total } \\
\text { examined }\end{array}$} & \multicolumn{2}{|c|}{$\begin{array}{c}\text { Paucibacillary } \\
\text { leprosy }\end{array}$} & \multicolumn{2}{|c|}{$\begin{array}{c}\text { Multibacillary } \\
\text { leprosy }\end{array}$} & \multicolumn{2}{|c|}{$\begin{array}{l}\text { All } \\
\text { leprosy }\end{array}$} \\
\hline & & cases & rate & cases & rate & cases & rate & & cases & rate & cases & rate & cases & rate \\
\hline $0-4$ & 9702 & 2 & $0 \cdot 2$ & 0 & - & 2 & $0 \cdot 2$ & 9990 & 0 & - & 0 & - & 0 & - \\
\hline $5-9$ & 8915 & 13 & $1 \cdot 5$ & 0 & - & 13 & $1 \cdot 5$ & 8966 & 13 & $1 \cdot 4$ & 0 & - & 13 & $1 \cdot 4$ \\
\hline $10-14$ & 6916 & 17 & $2 \cdot 5$ & 0 & - & 17 & $2 \cdot 5$ & 6577 & 32 & 4.9 & 1 & $0 \cdot 2$ & 33 & 5.0 \\
\hline $15-19$ & 5355 & 23 & $4 \cdot 3$ & 2 & 0.4 & 25 & $4 \cdot 7$ & 5073 & 21 & $4 \cdot 1$ & 0 & - & 21 & $4 \cdot 1$ \\
\hline $20-24$ & 3713 & 15 & $4 \cdot 0$ & 2 & 0.5 & 17 & $4 \cdot 6$ & 4411 & 26 & 5.9 & 2 & $0 \cdot 5$ & 28 & $6 \cdot 3$ \\
\hline $25-34$ & 5209 & 47 & $9 \cdot 0$ & 9 & 1.7 & 56 & $10 \cdot 8$ & 7582 & 67 & 8.8 & 2 & $0 \cdot 3$ & 69 & $9 \cdot 1$ \\
\hline $35-44$ & 4512 & 42 & $9 \cdot 3$ & 7 & $1 \cdot 6$ & 49 & $10 \cdot 9$ & 7329 & 77 & $10 \cdot 5$ & 3 & $0 \cdot 4$ & 80 & $10 \cdot 9$ \\
\hline $45-59$ & 5046 & 33 & $6 \cdot 5$ & 9 & $1 \cdot 8$ & 42 & $8 \cdot 3$ & 5630 & 70 & $12 \cdot 4$ & 2 & $0 \cdot 4$ & 72 & $12 \cdot 8$ \\
\hline$>60$ & 2762 & 15 & $5 \cdot 4$ & 4 & $1 \cdot 4$ & 19 & 6.9 & 2445 & 37 & $15 \cdot 1$ & 0 & - & 37 & $15 \cdot 1$ \\
\hline Total & 52130 & 207 & $4 \cdot 0$ & 33 & $0 \cdot 6$ & 240 & $4 \cdot 6$ & 58003 & 343 & 5.9 & 10 & $0 \cdot 2$ & 353 & $6 \cdot 1$ \\
\hline
\end{tabular}


received treatment from an institution or service other than the LCP (31\% for males and $16 \%$ for females). In addition it can be seen that the sex ratio varies considerably between ascertainment groups. The female proportion among all patients is lowest for the group ascertained elsewhere $(48 \%)$ and highest for those ascertained by the LEP $(60 \%)$. Among paucibacillary patients these percentages were $53 \%$ and $61 \%$ respectively.

Table 2 and Figure 3 show the prevalence rates of current clinical paucibacillary and multibacillary leprosy, attributable to present infection with $M$. leprae, by age and sex. The prevalence rates of current clinical paucibacillary leprosy rise to a peak in the 35-44 year age group among the males, but continue to rise with age in females. Thus there is little difference between the sexes up to the age of 25-34, while at older ages the prevalence rates of paucibacillary leprosy are higher for females. In addition, dips in the prevalence rates for paucibacillary leprosy can be seen in the 20-24 year age group among males and the 15-19 year age group among females. For current multibacillary disease the prevalence rates are only a fraction of those for current paucibacillary disease and are higher among males than among females.

The prevalence rates of visible leprosy (i.e. either current clinical signs of leprosy or else residual signs only) are shown in Figure 4 and Table 3. Among males the age-specific prevalence rates of visible paucibacillary leprosy rise to a peak of $27 \cdot 0$ per 1000 in the $45-59$ year age group. Among females the corresponding rate reaches its peak of 34.8 per 1000 in the oldest age group, over 60 years of age. Again, rates for visible multibacillary disease are much lower than those for visible

\section{LEP 1979 - $1984 \quad$ 'clinical' prevalence}

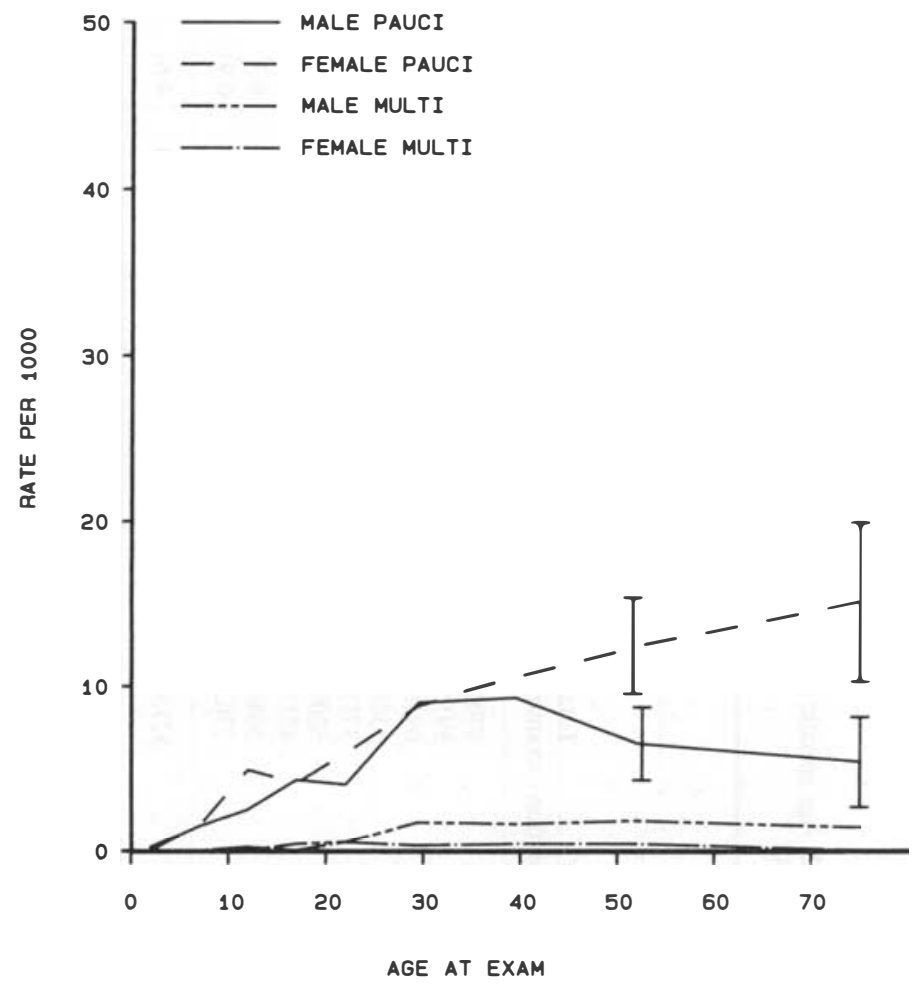

Figure 3. Prevalence rates of current clinical leprosy by type, sex and age at examination by the LEP in Karonga District, Malawii, 1979-84. Vertical bars indicate 95\% confidence intervals. 
LEP 1979 - 1984 'visible' prevalence

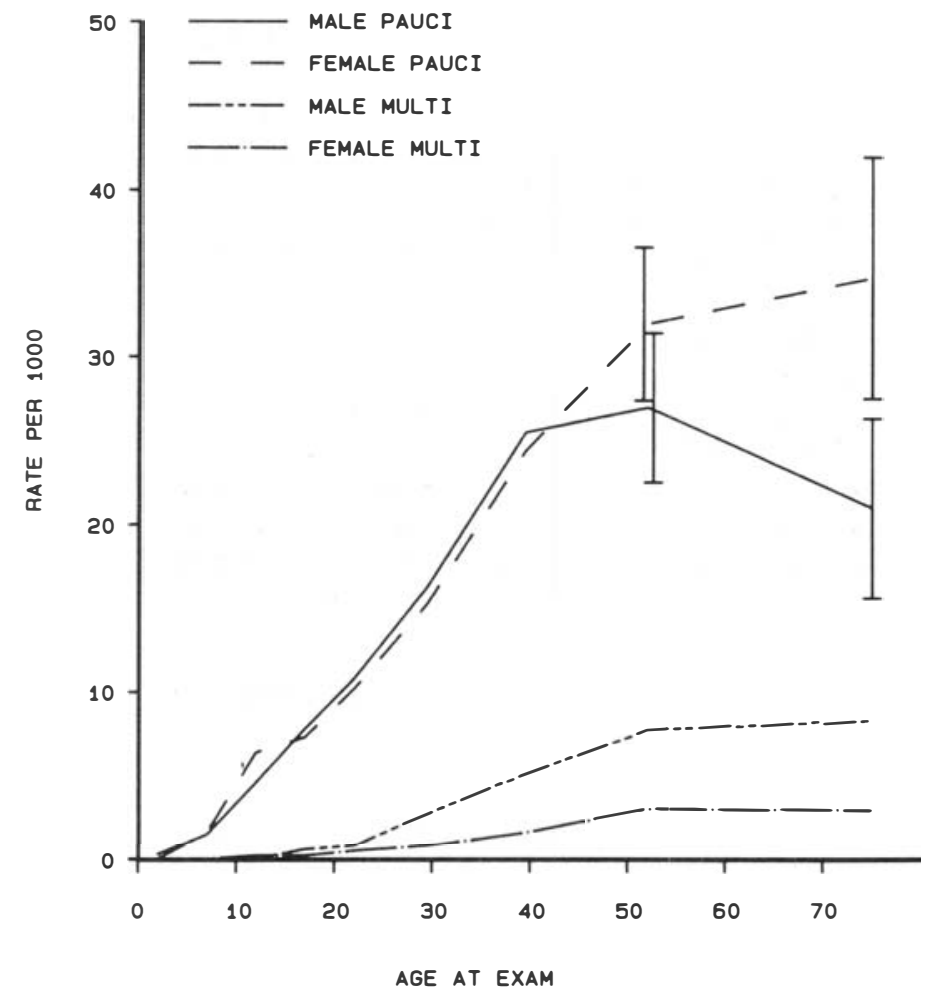

Figure 4. Prevalence rates of visible leprosy by type, sex and age at examination by the LEP in Karonga District, Malaŵi, 1979-84. Vertical bars indicate 95\% confidence intervals (off set so as not to overlap).

paucibacillary disease and three times as high for males as for females. Table 3 presents the visible rates by age and sex for visible paucibacillary and multibacillary leprosy combined. Table 3 also shows that the majority of older male patients were ascertained by an institution other than the LCP or the LEP. For older female individuals this proportion was only one third. Nearly all young (e.g. 5-14-year-old) patients were, in contrast, first ascertained by the LEP.

Figure 5 shows the age-specific cumulative prevalence rates of leprosy (including all individuals with current clinical signs, residual signs or a history of either). Though the rates are higher, the trends are similar to those of visible disease in Figure 4, except for 'bulges' in paucibacillary disease among the 15-24-year-old males and females. With regard to the mode of ascertainment it can be seen from Table 4 that the majority of older males were first ascertained 'elsewhere' but that this proportion was again much smaller for females. Approximately two thirds of the individuals in the 15-24 year age group were first ascertained by the LCP. This is appreciably higher than the proportion of individuals in this age group ascertained by the LCP and included in the visible rates (Table 3). This is particularly conspicuous for females.

Figure 6(a) and (b) show all three prevalence rates for paucibacillary and multibacillary leprosy together for males (Figure 6(a)) and for females (Figure 6(b)). They show again the large difference between the prevalence rates of clinical and visible leprosy and the relatively smaller difference between visible and cumulative leprosy at all except the very young ages.

Table 5 shows the relationship between visible and cumulative leprosy by age and sex, with 
Table 3. Visible prevalence statistics by age and sex, Karonga District, Malawii, 1979-84. For each age and sex the number and percentage (in parentheses) of leprosy cases ascertained by each mode are shown, and the prevalence rate per 1000. Denominators for these prevalence rates are in Table 2

\begin{tabular}{|c|c|c|c|c|c|c|c|c|c|c|}
\hline \multirow[b]{2}{*}{$\begin{array}{l}\text { Age at } \\
\text { examination } \\
\text { by LEP }\end{array}$} & \multicolumn{5}{|c|}{ Males } & \multicolumn{5}{|c|}{ Females } \\
\hline & $\begin{array}{l}\text { Ascertained } \\
\text { elsewhere }\end{array}$ & $\begin{array}{l}\text { Ascertained } \\
\text { by LCP }\end{array}$ & $\begin{array}{l}\text { Ascertained } \\
\text { by LEP }\end{array}$ & $\begin{array}{l}\text { Total } \\
\text { cases }\end{array}$ & $\begin{array}{l}\text { Visible } \\
\text { prev. rate } \\
\text { per } 1000\end{array}$ & $\begin{array}{l}\text { Ascertained } \\
\text { elsewhere }\end{array}$ & $\begin{array}{l}\text { Ascertained } \\
\text { by LCP }\end{array}$ & $\begin{array}{l}\text { Ascertained } \\
\text { by LEP }\end{array}$ & $\begin{array}{l}\text { Total } \\
\text { cases }\end{array}$ & $\begin{array}{l}\text { Visible } \\
\text { prev. rate } \\
\text { per } 1000\end{array}$ \\
\hline $0-4$ & 0 & 0 & $3(100 \%)$ & 3 & $0 \cdot 3$ & 0 & 0 & 0 & 0 & \\
\hline $5-9$ & 0 & 0 & $13(100 \%)$ & 13 & $1 \cdot 5$ & 0 & $1(7 \%)$ & $13(93 \%)$ & 14 & $1 \cdot 6$ \\
\hline $10-14$ & $0(3 \%)$ & $9(28 \%)$ & $22(69 \%)$ & 32 & $4 \cdot 6$ & 0 & $9(21 \%)$ & $34(79 \%)$ & 43 & $6 \cdot 5$ \\
\hline $15-19$ & $2(4 \%)$ & $17(38 \%)$ & $26(58 \%)$ & 45 & $8 \cdot 4$ & 0 & $17(45 \%)$ & $21(55 \%)$ & 38 & $7 \cdot 5$ \\
\hline $20-24$ & $5(12 \%)$ & $22(51 \%)$ & $16(37 \%)$ & 43 & $11 \cdot 6$ & 7 (15\%) & $14(30 \%)$ & $26(55 \%)$ & 47 & $10 \cdot 7$ \\
\hline $25-34$ & $19(19 \%)$ & $35(35 \%)$ & $45(45 \%)$ & 99 & $19 \cdot 0$ & $20(16 \%)$ & $33(27 \%)$ & $69(57 \%)$ & 122 & $16 \cdot 1$ \\
\hline $35-44$ & $62(45 \%)$ & $22(16 \%)$ & $54(39 \%)$ & 138 & $30 \cdot 6$ & $68(36 \%)$ & $47(25 \%)$ & $76(40 \%)$ & 191 & $26 \cdot 1$ \\
\hline $45-50$ & $109(62 \%)$ & $18(10 \%)$ & $48(27 \%)$ & 175 & $34 \cdot 7$ & $68(35 \%)$ & $38(19 \%)$ & $91(46 \%)$ & 197 & $35 \cdot 0$ \\
\hline$>60$ & $49(60 \%)$ & $12(15 \%)$ & $20(25 \%)$ & 81 & $29 \cdot 3$ & $31(34 \%)$ & $16(17 \%)$ & $45(49 \%)$ & 92 & $37 \cdot 6$ \\
\hline Total & $247(39 \%)$ & $135(21 \%)$ & $247(39 \%)$ & 629 & $12 \cdot 1$ & $194(26 \%)$ & $175(24 \%)$ & $375(50 \%)$ & 744 & $12 \cdot 8$ \\
\hline
\end{tabular}



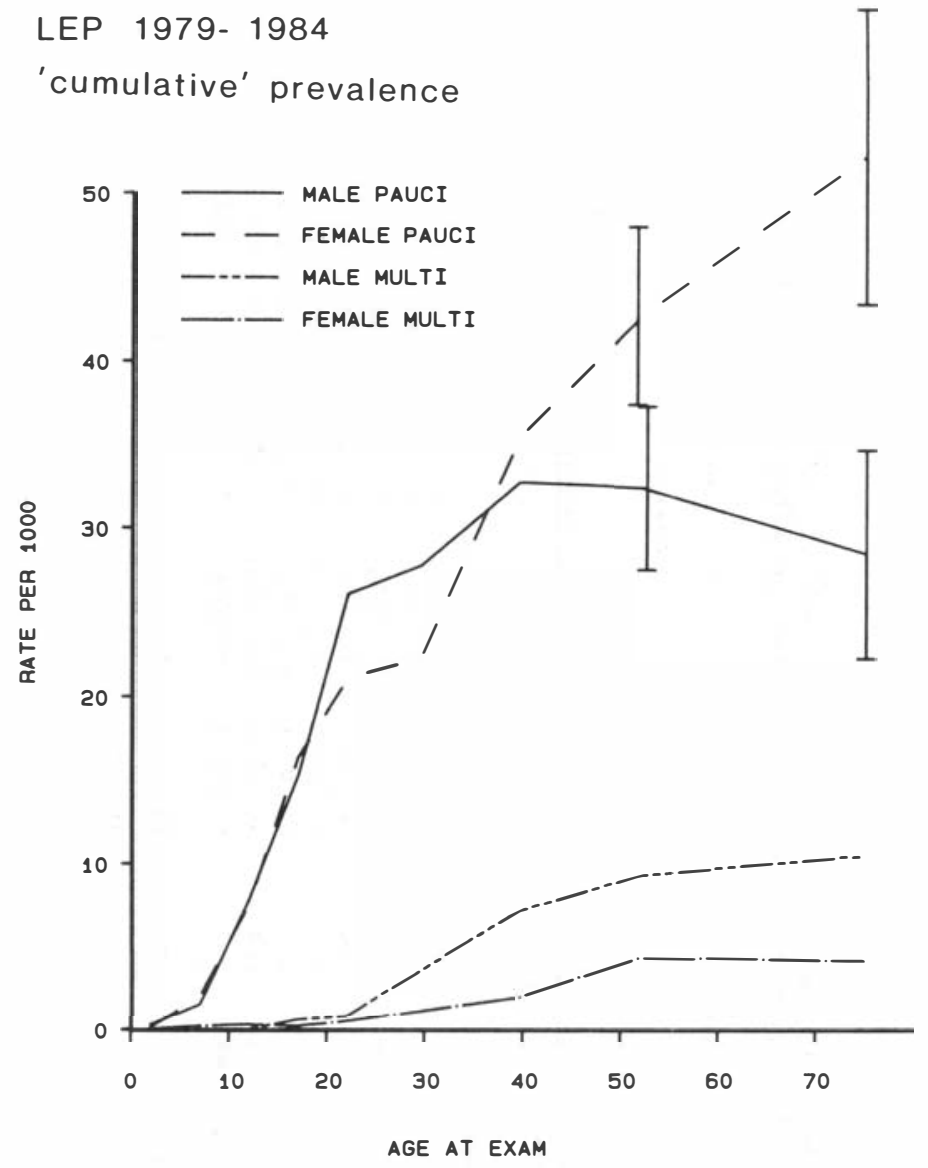

Figure 5. Cumulative prevalence rates of leprosy by type, sex and age at examination by the LEP in Karonga District, Malawi, 1979-85. Vertical bars indicate 95\% confidence intervals (off set so as not to overlap).

particular reference to cases first ascertained by the LCP. This shows that more than half of the patients first diagnosed by the LCP no longer had any residual signs of leprosy at the time of their first examination by the LEP.

\section{Discussion}

The analyses presented in this paper have attempted to address a widespread problem in leprosy endemic areas - the distortion of present disease patterns by past treatment programmes. In this context it should be noted that all of our measures are functions of historical circumstances and thus that their application may reveal very different patterns in diff erent areas of the world. Without the antileprosy treatment first given by Government Health Services and other institutions and later, since 1973, by the Lepra Control Project, the clinical and the visible prevalence rates would most likely have been higher, and the cumulative prevalence rate would have been lower, than observed here. In addition, in the total absence of historical information the visible and the cumulative rates would have been identical. Even now they are very similar in shape (Figure 6(a) and (b)).

Our cumulative prevalence rates of leprosy are undoubtedly underestimates of the total 
Table 4. Cumulative prevalence statistics by age and sex, Karonga District, Malawi, 1979-84. For each age and sex, the number and percentage (in parentheses) of leprosy cases ascertained by each mode are shown, and the prevalence rate per 1000 . Denominators for these prevalence rates are in Table 2

\begin{tabular}{|c|c|c|c|c|c|c|c|c|c|c|}
\hline \multirow[b]{2}{*}{$\begin{array}{l}\text { Age at } \\
\text { examination } \\
\text { by LEP }\end{array}$} & \multicolumn{5}{|c|}{ Males } & \multicolumn{5}{|c|}{ Females } \\
\hline & $\begin{array}{l}\text { Ascertained } \\
\text { elsewhere }\end{array}$ & $\begin{array}{c}\text { Ascertained } \\
\text { by LCP }\end{array}$ & $\begin{array}{l}\text { Ascertained } \\
\text { by LEP }\end{array}$ & $\begin{array}{l}\text { Total } \\
\text { cases }\end{array}$ & $\begin{array}{l}\text { Visible } \\
\text { prev. rate } \\
\text { per } 1000\end{array}$ & $\begin{array}{l}\text { Ascertained } \\
\text { elsewhere }\end{array}$ & $\begin{array}{l}\text { Ascertained } \\
\text { by LCP }\end{array}$ & $\begin{array}{l}\text { Ascertained } \\
\text { by LEP }\end{array}$ & $\begin{array}{l}\text { Total } \\
\text { cases }\end{array}$ & $\begin{array}{c}\text { Visible } \\
\text { prev. rate } \\
\text { per } 1000\end{array}$ \\
\hline $0-4$ & 0 & 0 & $3(100 \%)$ & 3 & $0 \cdot 3$ & 0 & $1(100 \%)$ & 0 & 1 & $0 \cdot 1$ \\
\hline $5-9$ & 0 & 0 & $13(100 \%)$ & 13 & $1 \cdot 5$ & 0 & $7(35 \%)$ & $13(65 \%)$ & 20 & $2 \cdot 2$ \\
\hline $10-14$ & $2(4 \%)$ & $30(56 \%)$ & $22(41 \%)$ & 54 & $7 \cdot 8$ & 0 & $17(33 \%)$ & $34(67 \%)$ & 51 & $7 \cdot 8$ \\
\hline $15-19$ & $3(4 \%)$ & $56(66 \%)$ & $26(31 \%)$ & 85 & $15 \cdot 9$ & 0 & $63(75 \%)$ & $21 \quad(25 \%)$ & 84 & $16 \cdot 6$ \\
\hline $20-24$ & $10(10 \%)$ & $74(74 \%)$ & $16(16 \%)$ & 100 & $26 \cdot 9$ & $9(9 \%)$ & $60(63 \%)$ & $26(27 \%)$ & 95 & $21 \cdot 5$ \\
\hline $25-34$ & $36(22 \%)$ & $82(50 \%)$ & $45(28 \%)$ & 163 & $31 \cdot 3$ & $29(16 \%)$ & $79(45 \%)$ & $69(39 \%)$ & 177 & $23 \cdot 3$ \\
\hline $35-44$ & $76(42 \%)$ & $50(28 \%)$ & $54(30 \%)$ & 180 & $39 \cdot 9$ & $97(35 \%)$ & $101(37 \%)$ & $76(28 \%)$ & 274 & $37 \cdot 4$ \\
\hline $45-59$ & $126(60 \%)$ & $37(18 \%)$ & $48(23 \%)$ & 211 & $41 \cdot 8$ & $96(36 \%)$ & $78(29 \%)$ & $91 \quad(34 \%)$ & 265 & $47 \cdot 1$ \\
\hline$>60$ & $58(54 \%)$ & $30(28 \%)$ & $20(19 \%)$ & 108 & $39 \cdot 1$ & $53(38 \%)$ & $40(29 \%)$ & $45(33 \%)$ & 138 & $56 \cdot 4$ \\
\hline Total & $311(34 \%)$ & $359(39 \%)$ & $247(27 \%)$ & 917 & $17 \cdot 6$ & $284(26 \%)$ & $446(40 \%)$ & $375(34 \%)$ & 1105 & $19 \cdot 1$ \\
\hline
\end{tabular}



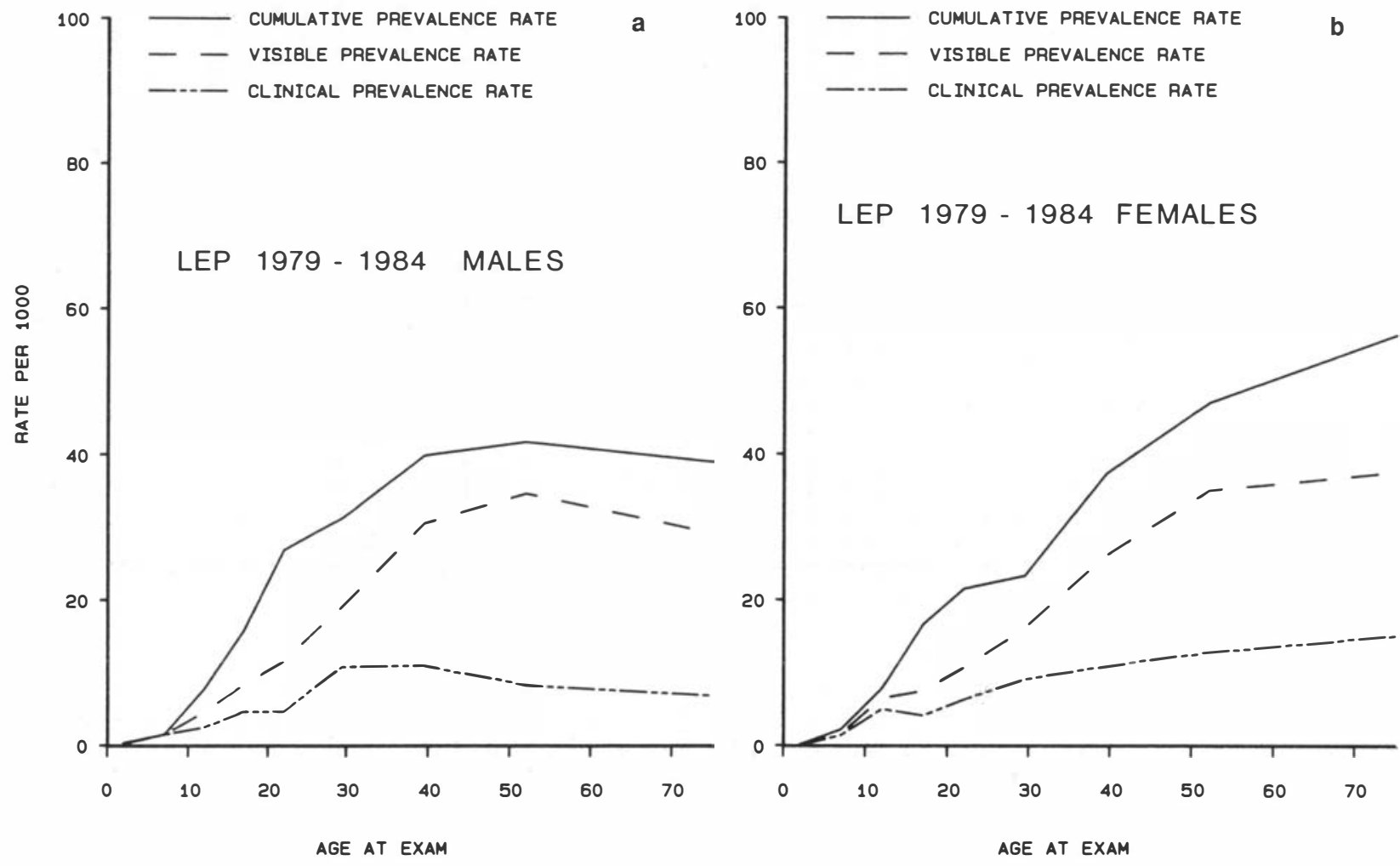

AGE AT EXAM

AGE AT EXAM

Figure 6(a) Prevalence rates of leprosy among males by age at examination and type of prevalence measure, for paucibacillary and multibacillary leprosy combined, in Karonga District, Malawii, 1979-84. (b) Prevalence rates of leprosy among females by age of examination and type of prevalence measure, for paucibacillary and multibacillary leprosy combined, in Karonga District, Malaŵi, 1979-84. 
Table 5. Percentages of leprosy patients first treated by LCP who were without clinical signs of leprosy at the time of examination by LEP staff during the 1979-84 survey

\begin{tabular}{lcccc}
$\begin{array}{l}\text { Age at } \\
\text { examination } \\
\text { by LEP }\end{array}$ & \multicolumn{2}{c}{ Males } & \multicolumn{2}{c}{ Females } \\
\hline $0-4$ & - & $(0 / 0)$ & $100 \cdot 0 \%$ & $(1 / 1)$ \\
$5-9$ & - & $(0 / 0)$ & $85 \cdot 7 \%$ & $(6 / 7)$ \\
$10-14$ & $70 \cdot 0 \%$ & $(21 / 30)$ & $47 \cdot 1 \%$ & $(8 / 17)$ \\
$15-19$ & $69 \cdot 6 \%$ & $(39 / 56)$ & $73 \cdot 0 \%$ & $(46 / 63)$ \\
$20-24$ & $70 \cdot 3 \%$ & $(52 / 74)$ & $76 \cdot 7 \%$ & $(46 / 60)$ \\
$25-34$ & $57 \cdot 3 \%$ & $(47 / 82)$ & $58 \cdot 2 \%$ & $(46 / 79)$ \\
$35-44$ & $56 \cdot 0 \%$ & $(28 / 50)$ & $53 \cdot 5 \%$ & $(54 / 101)$ \\
$45-59$ & $51 \cdot 4 \%$ & $(19 / 37)$ & $51 \cdot 3 \%$ & $(40 / 78)$ \\
$>60$ & $60 \cdot 0 \%$ & $(18 / 30)$ & $60 \cdot 0 \%$ & $(24 / 40)$ \\
All ages & $62 \cdot 4 \%$ & $(224 / 359)$ & $60 \cdot 8 \%$ & $(271 / 446)$ \\
\hline
\end{tabular}

proportions of individuals who ever manifested clinical signs of leprosy, in so far as it is likely that a number of individuals contracted self-healing forms of the disease which never came to the attention of either the LCP or the LEP. Such underestimation should have been cumulative over time; and thus should be particularly great for older age groups. The degree of underestimation should also be considerably greater for paucibacillary than for multibacillary forms of the disease, given that multibacillary forms of leprosy are unlikely to self-heal without leaving residual signs. The high proportion of multibacillary disease (Table 1) in the past is therefore considered to be an 'artefact' due in part to misclassification and in part to the mode of detection of these cases. In addition there has been a rise in the proportion of females among patients over time (Table 1) which may indicate that in the past self-reporting was less common among females than among males. If a substantial proportion of their lesions self-healed then our cumulative rates also selectively underestimate the true rates in older females. Although we recognize the cumulative prevalence rates to be underestimates, we did not attempt to investigate histories further, as we were sceptical of the reliability of such information. Nevertheless, the measure is of considerable interest as evidence that more than $4 \%$ of males and more than $5 \%$ of females in this population manifest clinical leprosy lesions at some time in their lives if they live to the age of 60 .

Our prevalence rates of visible leprosy might have been inflated slightly by the inclusion of middle ('probable') group patients, in a proportion of whom the clinical signs may not have been due to past or present infection with $M$. leprae. This overestimation is likely to be small however, since the majority of all patients were in the narrow ('certain') group (54\% overall) and we have presented evidence elsewhere ${ }^{7}$ that the diagnostic specificity among middle group patients ascertained by the LEP is high. Furthermore, the inclusion of a few false positives should have been compensated by the omission of a few genuine leprosy cases allocated into the wide (possibly leprosy) group.

Among males there is a fall in the clinical, visible and cumulative prevalence rates of paucibacillary leprosy after age 60 (Figures 3, 4 and 5). No such fall is seen among females, where the visible and cumulative rates are highest among those over 60 years of age. The reason for these differences between the sexes is not obvious. Possibilities include higher selective mortality and/or emigration among males, but we have no data to support or refute either hypothesis. In addition one could speculate that because the majority of older males spent many years of their lives outside the District, working in the mines in Tanzania, Zambia, Zimbabwe and South Africa, ${ }^{15}$ the incidence rates were lower among them than among females, who usually remained in Karonga District throughout their lives. 
Apart from the prevalence rates of visible and of cumulative leprosy we have also tried to estimate the prevalence rate of clinical leprosy. This prevalence rate is likely to be an underestimate in so far as a proportion of apparently inactive paucibacillary leprosy lesions might nevertheless contain viable $M$. leprae. Such cases are now included only in the visible prevalence rate. In spite of this problem we believe this rate provides a more appropriate and usef ul indicator of the actual need for antileprosy treatment facilities than does the prevalence rate of visible leprosy. The majority of 'patients' included in the visible prevalence rate are unlikely to benefit from (further) specific antileprosy treatment - though they might of course be in need of physiotherapy, ulcer care or social support. If tests become available which can recognize the presence of $M$. leprae infection it should become possible to determine this prevalence rate of clinical leprosy more accurately. Such tests would hopefully also be able to recognize the presence of dormant $M$. leprae (persisters) in individuals with residual signs only or in individuals with no remaining signs. Such individuals would then be included in the infection prevalence group, on the size, age and sex trends of which we can only speculate at present. ${ }^{16}$

It is of interest that the prevalence rates of clinical leprosy rise consistently with age except among males aged 20-24 and among females aged 15-19. These inconsistencies may be biologically significant. Two possible explanations offer themselves:

(1) The LCP had an active case-finding programme among school children between 1974 and 1979. Unfortunately, the exact number of new leprosy patients found during those school surveys is not known. However, the number was probably substantial (Table 4). The present prevalence rates of clinical leprosy might thus be low among 15-19 and 20-24 year old individuals because leprosy was diagnosed and treated at an early stage in individuals in this age group when they were attending school.

(2) BCG has been widely used in Karonga District since the mid-seventies both in mass campaigns among school children and in under-five clinics. Because mass campaigns were discontinued in the late seventies the prevalence rate of BCG scars was highest among males aged $15-24$ years $(76 \cdot 5 \%)$ and among females aged $15-19$ years $(74 \cdot 2 \%)$ at the time of the survey. This observation, together with our evidence of at least $50 \%$ protective efficacy of BCG against leprosy in this area, ${ }^{17}$ suggests a causal relationship between $\mathrm{BCG}$ and the dip in prevalence rates among females and males respectively. However, these dips are not seen in the cumulative rates, where the rates seem more to 'bulge' for these age groups. The answer to this puzzle might be that those who had no signs of leprosy left at the time of examination by the LEP had onset of disease around the time of BCG vaccination or before, while most of these found with current clinical signs of leprosy had onset of disease after the introduction of BCG into the District. Only among the latter can one expect an effect of BCG. The bulge among the former could thus be due to overdiagnosing during school surveys or diagnosing of early self-healing forms during school surveys. Alternatively, it might be that the BCG vaccinations precipitated mild self-healing forms of leprosy among vaccines bef ore the long term protective effect became evident. ${ }^{18,19}$

We believe it is useful to describe the prevalence of leprosy using three different prevalence rates rather than only one. Only $43 \%$ (593/1367) of individuals with visible signs of leprosy, skin lesions and/or disabilities had (active) clinical disease, presumably requiring antileprosy treatment, at the time of being examined by the LEP. The prevalence of clinical disease is more relevant to treatment facility needs than is the prevalence of visible leprosy. On the other hand, the cumulative prevalence rate (including those with well-documented histories of clinical leprosy) gives a more realistic impression of the extent of leprosy in the past and of the achievements of a control project. Presumably largely due to treatment, only about $40 \%$ of leprosy patients treated exclusively by the LCP in Karonga District are left with any signs of leprosy. The extent of disability among these individuals is currently under investigation.

In view of our findings that only two-fifths of all individuals with visible signs of leprosy had clinically active disease or were found with $M$. leprae in slit-skin smears or biopsies, and would thus benefit from (further) antileprosy treatment, we wonder how many of the world's 10-12 million 
leprosy "cases' 20 are really leprosy patients in the sense that they require specific antileprosy treatment rather than physiotherapy, ulcer care, or social and economic support.

\section{Acknowledgments}

The authors wish to thank the Government of the Republic of Malawi for their interest in the Lepra Evaluation Project. Without their support and the co-operation from the people in Karonga District the project would not have been possible.

The Lepra Evaluation Project staff worked hard for many years to obtain the data analysed in this publication but the authors would also acknowledge the Lepra Control Project staff, in particular Mr P Nankhuni and Mr K Mughandira, for making available all information on previous LCP patients.

Funding for the Lepra Evaluation Project is provided by the British Leprosy Relief Association (LEPRA).

\section{References}

1 WHO Study Group. Epidemiology of leprosy in relation to control. Technical Report Series No. 716. WHO: Geneva, 1985.

2 Doull SA, Guinto RS, Rodriguez JN, Bancroft H. The incidence of leprosy in Cordova and Talisay, Cebu, Philippines. Int J Lep, 1942; 10: 107-31.

${ }^{3}$ Bechelli LM, Dominguez VM, Patwary KM. WHO epidemiologic random sample surveys of leprosy in northern Nigeria (Katsina), Cameroon and Thailand (Kohn Kaen). Int J Lepr, 1966; 34: 223-43.

${ }^{4}$ Bechelli LM, Gallego Garbajosa P, Gyi MM, Uemura K, Sundaresan T, Tamundong C, MartinezDominguez V, Walter J. Some epidemiological data on leprosy collected in a mass survey in Burma. Bull WHO, 1973; 48: 335-44.

${ }^{5}$ Rao PSS, Karat ABA, Kaliaperumal UG, Karat S. Prevalence of leprosy in Gudiyatham Taluk, South India. Part I. Specific rates with reference to age, sex, and type. Int J Lepr, 1972; 40: 157-63.

${ }^{6}$ Fine PEM. Leprosy: the epidemiology of a slow bacterium. Epidemiol Rev, 1982; 4: 161-88.

7 Ponnighaus JM, Fine PEM, Bliss L. Certainty levels in the diagnosis of leprosy. Int J Lepr, 1987, 55: 454-62.

${ }^{8}$ Burgess PJ, Fine PEM, Ponnighaus JM, Draper C. Serological tests in leprosy. The sensitivity, specificity and predictive value of ELISA tests based on phenolic glycolipid antigens and the implications for their use in epidemiological studies. Epidemiol Infect, in press.

" Pettit JHS. Should indeterminate leprosy ever be diagnosed" (Letter to the editor.) Int J Lepr, 1981; 49: ys-6.

${ }^{10}$ Ponnighaus JM, Fine PEM, Bliss Lyn, Sliney I, Bradley D, Rees RJW. The Lepra Evaluation Project (LEP), an epidemiological study of leprosy in Northern Malawi. I: Methods. Lepr Rev, 1987; 59: 359-75.

${ }^{11}$ McDougall AC, Ponnighaus JM, Fine PEM. The histopathological examination of skin biopsies from an epidemiological study of leprosy in Northern Malawi. Int J Lepr, 1987; 55: 88-98.

12 Boerrigter G, Ponnighaus JM. 10 years' leprosy control work in Malawi (Central Af rica) - 1, Methods and outcome af ter treatment. Lepr Rev, 1986; 57: 199-220.

13 Committee on Classification. Technical resolutions: classification. Int J Lepr, 1953; 21: 504-16.

14 Ridley DS, Jopling WH. Classification of leprosy according to immunity-a five-group system. Int J Lepr, 1966; 34: 255-73.

${ }^{15}$ Committee appointed by His Excellency the Governor of Nyasaland. Report of an Inquiry into Emigrant Labour, 1935.

${ }^{16}$ Fine PEM, Ponnighaus JM, Burgess P, Clarkson JA, Draper CC. Seroepidemiological studies of leprosy in Northern Malawi based on an enzyme-linked immuno-sorbent assay using synthetic glycoconjugate antigen. Int $J$ Lepr, in press.

${ }^{17}$ Fine PEM, Ponnighaus JM, Maine N, Clarkson JA, Bliss L. Protective efficacy of BCG against leprosy in Northern Malawii. Lancet, 1986; ii: 499-502.

18 Wade HW. BCG induced activations. Int J Lepr, 1960; 28: 179-81.

${ }^{19}$ Lwin K, Sundaresan T, Gyi MM, Bechelli LM, Tamondong C, Gallego Garbajosa P, Sansarricq H, Noordeen SK. BCG vaccination of children against leprosy: fourteen year findings of the trial in Burma. Bull WHO, 1985; 63: 1069-78.

20 Noordeen SK. The epidemiology of Leprosy. In: Leprosy. Hastings RC (ed). Churchill Livingstone: 1985, Edinburgh, London, Melbourne, New York. 